\title{
ALLEVIATION OF URBAN POVERTY THROUGH DAY-NULM SCHEME: A STUDY WITH REFERENCE TO GUWAHATI CITY
}

\author{
Durlav Kumar Barman \\ Assistant Professor, Arya Vidyapeeth College, Gopinath Nagar, Guwahati, India \\ Trishna Saloi \\ Assistant Professor, Guwahati College, Bamunimaidan, Guwahati, India
}

\begin{abstract}
Urban poverty is becoming a significant area of concern. Despite the better production and marketing facilities of urban areas and the higher consumption capacity of urban populations the urban poor are growing more rapidly than the rural poor and more emphasis should be given to reducing urban poverty. The government of India has finally come up with innovative solutions to creating choices for the urban poor through various solutions and multiple dimensions. One of such program is DAY-NULM (Deendayal Antyodaya Yojana- National Urban Livelihoods Mission). In Assam DAY-NULM is operating under ASULM (Assam State Urban Livelihoods Mission Society). This scheme aims to reduce poverty and vulnerability of the urban poor households by enabling them to access gainful self employment opportunities, providing shelters equipped with essential services to the urban homeless in a phased manner, also address livelihood concerns of the urban street vendors by facilitating access to suitable spaces, institutional credit, social security and skills to the urban street vendors for accessing emerging market opportunities. Thus the present paper is an attempt to study the implementation and progress of the scheme since its inception in Guwahati city,
\end{abstract}

Key words: Urban Poverty, Livelihood, DAY-NULM, ASULM

Cite this Article: Durlav Kumar Barman and Trishna Saloi, Alleviation of Urban Poverty through DAY-NULM Scheme: A Study with Reference to Guwahati City, International Journal of Management, 11(12), 2020, pp 1148-1155.

http://iaeme.com/Home/issue/IJM?Volume=11\&Issue=12

\section{INTRODUCTION}

Poverty has always been a fundamental concern of development planning in India. Indeed, poverty is a global issue. Its eradication is considered integral to humanity's quest for sustainable development. Reduction of poverty in India is, therefore, vital for the attainment 
of national and international goals. Poverty has many dimensions, it certainly involves lack of human and physical asset and inadequate material means to acquire food and other necessities. But also means vulnerability to ill-health, drought, job loss, economic decline, violence and societal conflicts. According to Ian Robertson (2013), "Poverty is the inability to maintain minimal standards of food, clothing, shelter and health care". Although cities are centers of production, employment and innovation, the rapid urbanization also manifests itself in the form of congestion, inadequate infrastructure, housing shortage, poor access to basic urban services and proliferation of slums with degraded environment. Indeed, urban poverty is the poverty of the resident of urban areas who might be migrated from rural areas or born and brought up in the urban area living with lack of basic amenities for several decades. In India apart from the contemporaneous migration of the rural poor to urban areas, urban poverty has expanded in urban areas itself with the original migrant family remaining poor but becoming larger. One of the most remarkable features of urban poverty is the spectacular growth of urban population in India due to rapid urbanization. (Malali, R., 2016)

The government of India has finally come up with innovative solutions to creating choices for the urban poor through various solutions and multiple dimensions. One of such program is DAY-NULM (Deendayal Antyodaya Yojana- National Urban Livelihoods Mission). It was launched by the Ministry of Housing and Urban Poverty Alleviation (MHUPA), Government of India in 23rd September, 2013 by replacing the existing Swarna Jayanti Shahari Rozgar Yojana (SJSRY). The NULM is focus on organizing urban poor in their strong grassroots level institutions, creating opportunities for skill development leading to market-based employment and helping them to set up self-employment venture by ensuring easy access to credit. The Mission is aimed at providing shelter equipped with essential services to the urban homeless in a phased manner. In addition, the Mission would also address livelihood concerns of the urban street vendors.

This paper includes an overall study of urban poverty in Guwahati city. As the increasing numbers of people who have taken up residence in Guwahati city and the large scale urbanization that has gained momentum due to the multifunctional character of the city has created serious problem in respect of urban facilities. According to a survey done by a UK media outlet, Guwahati is among the 100 fastest growing cities of the world, and is the 5th fastest growing among Indian cities (Dr. Chetia, P., 2014). Guwahati, the capital of Assam being the gateway to North-East India has attracted a lot of people and therefore we tend to find slum formation in many over crowed areas where basic amenities like water, drainage etc. are lacking. So, to overcome this problem the government of India has introduced the scheme DAY-NULM (Deendayal Antyodaya Yojana- National Urban Livelihoods Mission). In Assam DAY-NULM is operating under ASULM (Assam State Urban Livelihoods Mission Society). Therefore, this paper is an attempt to study the implementation and progress of the scheme since its inception in Guwahati city and it will also highlight the effectiveness of the scheme in the study area.

\section{OBJECTIVES OF THE STUDY}

The study has been carried out keeping in mind the following objectives:

- To study the role of DAY-NULM scheme in alleviation of urban poverty Guwahati city;

- To study the operation of of DAY-NULM scheme in Guwahati city, Assam;

- To examine loopholes, if any, in implementation of the scheme in Guwahati city. 


\section{METHODOLOGY OF THE STUDY}

The methodology adopted in this study has been outlined as below:

Area of Study: The study is concentrated on implementation and progress of ASULM in Guwahati city.

Sources of Data: Data have been collected from both primary and secondary sources. The researcher has used questionnaires and personal interview method to draw the required information. A face-to-face interview was undertaken with the officials of the Guwahati Municipal Corporation, Lakhtokia. The questionnaires was prepared in order to elicit information regarding:

- The number of peoples who have taken these schemes.

- Types of schemes implemented under DAY-NULM.

- What are the problems faced by the officials during implementation of the schemes.

- Are the beneficiaries receiving the fund on time.

- Whether these schemes help in reduction of urban poverty.

The secondary data have been extracted from various journals, newspaper articles, and official websites and so on. The office of the Guwahati Municipal Corporation, Lakhtokia also forms the source of secondary data.

\section{ROLE OF DAY-NULM SCHEME IN REDUCTION OF URBAN POVERTY}

As urban poverty being a multi-dimensional, various vulnerabilities faced by the poor in cities and towns like occupational, residential and social needs to be addressed simultaneously in a comprehensive and integrated manner with a targeted focus on the vulnerable groups so that a definitive impact can be made on ground. Urban poverty alleviation programmes need to be based on skill development and easy access to credit. With a view to alleviate urban poverty, NULM came with a mission-mode approach for urban livelihoods. The following are some of the important components of DAY-NULM programmes in Assam:

\section{a) Social Mobilisation \& Institution Development (SM \& ID)}

The Assam State Urban Livelihoods Mission strongly believes that the mobilisation of urban poor households to form their own institutions is an important investment for an effective and sustainable poverty reduction programme. The Mission envisages mobilisation of urban poor households into a three tiered structure with Self-Help Groups (SHGs) at the grass-root level, Area Level Federations (ALFs) at the slum/ward level and City Level Federations (CLFs) at the city level.

Formation of SHGs: SHG is a group of 10 to 20 urban poor women, formed with an objective of doing credit and thrift among themselves, income generation and manifold social activities. The Mission will provide Revolving Fund amounting Rs. 10,000/- to SHGs to form the bulk of the group. The basic eligibility for getting RF is that a SHG should be functional for a period of at least three (3) months and thereafter, SHGs will be graded on the basis of 'PANCHASUTRA'. The ground rules for every SHG is to follow the 'PANCHASUTRA' as under: Regular Meeting, Regular Saving, Internal Lending, Timely repayment of loan and Maintenance of Books of record.

Area Level Federation (ALF): It is an association/federation of 10 to 20 SHGs located in the same ward/locality. The objective of ALF is to support member SHGs, their capacity building, bank linkage, convergence with various agencies for support etc. The ALF will be 
registered under Assam Cooperative Societies Act, 2007. Registered ALFs will receive Rs.50,000/- as revolving fund.

City Level Federation (CLF): All ALFs in a city and town are to be represented at the CLF and it will work with ALFs, member SHGs, line departments and financial institutions to ensure social and economic empowerment.

\section{b) Employment through Skills Training \& Placement (EST \& P)}

Employment through Skills Training \& Placement (EST\&P) is a component under DAYNULM which is designed to provide skills to the unskilled urban poor as well as to upgrade their existing skills. The objective of the skills training under this component is to provide salaried job (in private sector) or self-employment through training in structured, market oriented certified courses, thereby increasing income and livelihoods of urban poor and increase their standard of living. There are various sectors and many courses under each sector available where training is given. Some of the prominent sectors where training can be given are Automotive Repairs, Electrical, Electronics, Telecom, Retail, Tourism \& Hospitality, Aviation, Security, Health Care, Beauty \& Wellness, Construction, Fabrication, Plumbing, Construction, Telecommunication, Fast Moving Consumer Goods (FMCG), Information Technology, etc. The Trainings are provided by Skills Training Providers (STPs) selected by DAY-NULM based on certain criteria and parameters. Trainings are provided mainly through National Skill Development Corporation (NSDC) empanelled Agencies or through other reputed Agencies who are empanelled by Assam State Urban Livelihoods Mission Society (ASULMS) prior to start of training and all trainings are Free of Cost which includes boarding \& lodging (in case of residential training).

\section{c) Self Employment Programme (SEP)}

This component will focus on financial assistance to individuals/groups of urban poor for setting up gainful self-employment ventures/ micro-enterprises, suited to their skills, training, aptitude and local conditions. The under-employed and unemployed urban poor will be encouraged to set up small enterprises relating to manufacturing, servicing and petty business for which there is considerable local demand. Local skills and local crafts should be particularly encouraged. No minimum or maximum educational qualification is prescribed for the selection of beneficiaries under SEP. The percentage of women beneficiaries under SEP shall not be less than 30 percent. SCs and STs must be benefited at least to the extent of the proportion of their strength in the city population of poor.

- Under this component, setting up of both individual and group micro enterprises will be supported. The project cost ceiling will be Rs. 2.00 lakh for individual enterprises and Rs. 10 Lakhs for group enterprises. Individual and groups may be provided loan from the banks and the application for such loans be preferably recommended by the SHGs.

- Interest subsidy over and above 7 percent rate of interest will be available on a bank loan for setting up of an individual or group enterprise. No collateral is envisaged other than the microenterprise itself.

- Also, Interest Subsidy over and above 7 percent rate of interest will be applicable to all SHGs accessing bank loan. An additional 3 percent interest subvention will be provided to all women SHGs who repay their loan in time in all the cities.

- The interest subvention will be subject to timely repayment by the beneficiaries. Suitable Certification from banks will be obtained in this regard. The difference between 7 percent or 4 percent as the case may be and the prevailing rate of interest will be provided to banks under NULM. 


\section{d) Shelter for Urban Homeless (SUH)}

Urban homeless persons who live without shelter or social security/protection are the most vulnerable class, even while they contribute towards sustaining cities with their cheap labour. Life on the streets involves surviving continuously at the edge, in a physically brutalized and challenging environment. There is a need for appropriate policy intervention to address the challenges faced by homeless people, with regard to shelter, social housing and social protection. So DAY-NULM aim at providing shelters equipped with essential services to the urban homeless in a phased manner. It is being monitored by the honourable Supreme Court of India. The sole aim of the Govt. and the Supreme Court is to help the poorest of the poor with a place to stay.

\section{e) Support to Urban Street Vendors (SUSV)}

This component aims at skilling of street vendors, support micro-enterprise development, credit enablement and pro-vending urban planning along with supporting social security options for vulnerable groups such as women, SCs/STs and minorities. Up to 5 percent of the total NULM budget will be spent on this component. Under NULM, states and cities will conduct a periodic socio-economic survey of street vendors, register street vendors and will issue Identity cards for street vendors. A database of street vendors will be development and maintained at city. This will enable States to prepare pro-vending urban planning and provide space for street vending. Poor and street vendors in urban areas can access skill training under the EST\&P component of NULM and micro-enterprise development support under the SEP component of NULM. They will be also encouraged to access basic banking services. Additionally, efforts will be made to cover individual beneficiaries with Credit Cards so as to enable street vendor's access for working capital and other purposes.

\section{f) Innovative \& Special Projects (I \& SP)}

This component will focus on the promotion of novel initiatives in the form of innovative projects. These initiatives may be in the nature of pioneering efforts, aimed at catalyzing sustainable approaches to urban livelihoods through Public, Private, Community Partnership (P-P-C-P), demonstrating a promising methodology or making a distinct impact on the urban poverty situation through scalable initiatives. The projects must demonstrate strategies to create long-term and sustainable livelihood opportunities and may cover organisation of the urban poor, formulation and implementation of innovative skill development programme, provision of support infrastructure, technology, marketing, capacity building, etc. or a combination of these. Innovative / special projects may be undertaken on a partnership mode involving CBOs, NGOs, semi-government Organisations, private sector, industry associations, government departments/ agencies, urban local bodies, national/state/city resource centers or international organizations. For this component, 5 percent of the total Central funds will be used. This will be centrally administered and no state share provision will be needed. Special projects covering proposals under any of the components will be implemented directly by the National Mission Directorate.

\section{FINDINGS AND DISCUSSIONS}

The introduction of DAY-NULM programme by the government is a significant step to reduce urban poverty in India. This programme was introduced in 2013 but in Assam it was started in the last month of 2014 and this programme is known as ASULM (Assam State Urban Livelihoods Mission Society). As Guwahati is the capital city of Assam the problem of urban poverty in the city is addressed by various researchers as well as the government. Thus this programme was introduced. To collect information regarding implementation and 
progress of this programme, the office of Guwahati Municipal Corporation, Lakhtokia was visited. Based on the information received the various officials, the major findings of the study are as following:

- There are 85,480 approx. (Source: Guwahati Municipal Corporation (GMC) Office, Lakhtokia) beneficiaries of all the schemes under ASULM programme during 2014-2017 in Guwahati city.

- The various schemes under ASULM in Guwahati city are:

○ Social Mobilisation \& Institution Development (SM \& ID)

- Self-Help Groups (SHGs)

- Area Level Federations (ALFs)

- City Level Federations (CLFs)

○ Employment through Skills Training \& Placement (EST \& P)

- Shelter for Urban Homeless (SUH)

- Support to Urban Street Vendors (SUSV).

- The number of Self-Help Groups (SHGs) operating under this programme during 2017-2020 are:

Table 1

\begin{tabular}{|l|l|}
\hline \multicolumn{1}{|c|}{ YEARS } & \multicolumn{1}{c|}{ NO. OF SHGs } \\
\hline $2013-2014$ & 114 approx.( SJSRY) \\
\hline $2014-2015$ & 32 (both NULM \& SJSRY) \\
\hline $2015-2016$ & 206 (NULM) \\
\hline $2016-2017$ & 618 (NULM) \\
\hline $2017-2018$ & 1400 (NULM) \\
\hline \multicolumn{2}{|c|}{ Source: Guwahati Municipal Corporation (GMC) Office, Lakhtokia }
\end{tabular}

The Mission provides Revolving Fund amounting Rs. 10,000/- to SHGs to form the bulk of the group. The basic eligibility for getting RF is that a SHG should be functional for a period of at least three (3) months and thereafter, SHGs will be graded on the basis of 'PANCHASUTRA'. The ground rules for every SHG is to follow the 'PANCHASUTRA' as under: Regular Meeting, Regular Saving, Internal Lending, Timely repayment of loan and Maintenance of Books of record.

- During the survey it was found that 20 Area Level Federations (ALFs) have been formed under this programme in the city and they receive Rs. 50,000 as a revolving fund. But till now no City Level Federations (CLFs) have been formed in Guwahati city.

- Under Self Employment Programme (SEP) setting up of both individual and group micro enterprises will be supported. The project cost ceiling is Rs. 2.00 lakh for individual enterprises and Rs. 10 Lakh for group enterprises. Individual and groups may be provided loan from the banks and the application for such loans be preferably recommended by the SHGs. During 2015-2017, 40\% of the individual beneficiaries received financial assistance under this programme.

- Under Shelter for Urban Homeless (SUH), urban homeless persons are provided shelters equipped with essential services. There are 5 night shelters under Department of Social welfare by ASULM :

- Indian Council for Child Welfare (ICCW) is located at Ambari, Guwahati. It provides shelter to both women \& child. 
- Snehalaya is a shelter home for boys only which is located at Paltanbazar, Guwahati.

- Eastern People Community Participation (EPCP) provides shelter to working men which is located at Sixmile, Guwahati.

- North East Voluntary Association of Rural Development (NEVARD) is a shelter home for both men \& women. It is located at Kahilipara, Guwahati.

- Golaghat Nirman Mahila Got provides shelter home for women \& child which is located at Sixmile, Guwahati.

Apart from the above shelter homes construction of some more shelters in the city are going on to provide shelter to 300(Source: Lakhtokia GMC Office) urban homeless

- Employment through Skills Training \& Placement (EST\&P) is designed to provide skills to the unskilled urban poor as well as to upgrade their existing skills. There are 17 EST\&P operating in Guwahati city affiliated under National Skill Development Council (NSDC) \& Sector Skill Council. During the survey it was found that out of 65 courses only 35 courses have been started in Guwahati by the following institution: ICON Academy of Professional Studies, SADBA Institute of Technology \& Management, Jazzy an Educational Society, The George Telegraph Training Institute, Asian Infotech, Ascensive Educare Pvt Ltd, B Able, Best First Step Pvt Ltd, Brainware, Britti Prosikshan Pvt Ltd, Edubridge, Indus Integrated Information Management Ltd, Orion Edutech, Rooman Technologies, Salt Lake and Skills Academy.

- Under this schemes training is provided free of cost to the unemployed youth. Till now 200 training programmes have been completed and 80 trainee got placement in different private sector companies like KFC, Tanishq, Big Bazaar, etc located in Assam, Bangalore, Pune, etc.

- Support to Urban Street Vendors (SUSV) aims at skilling of street vendors, support micro-enterprise development, credit enablement and pro-vending urban planning along with supporting social security options for vulnerable groups such as women, $\mathrm{SCs} / \mathrm{STs}$ and minorities. Up to 5 percent of the total NULM budget is spent on this component. ASULM conducted economic survey of 7,200 approx. street vendors in the city. Out of which only 50 street vendors got upto 6 lakhs for renovation and development and rest of them are still in progress.

- After interviewing the officials of the schemes regarding various problems faced by them during the implementation of the various schemes under ASULM, are Non availability of proper BPL survey report, Lack of transparency, Lengthy process, Political influence, Broad geographical area for survey and Lack of self- sufficiency among beneficiaries.

\section{CONCLUSION}

Urban poverty being a multi-dimensional, various vulnerabilities faced by the poor in cities and towns like occupational, residential and social need to be addressed simultaneously in a comprehensive and integrated manner with a targeted focus on the vulnerable groups so that a definitive impact can be made on ground. As the increasing numbers of people who have taken up residence in Guwahati city and the large scale urbanization that has gained momentum due to the multifunctional character of the city has created serious problem in respect of urban facilities. This type of flow is bound to create slums in the long run, irrespective of the fact, whether it is an industrial city or not. Assam being the gateway to North-East India has attracted a lot of people and therefore we tend to find slum formation in 
many over crowed areas where basic amenities like water, drainage etc. are lacking. In order to overcome these problems the government of India has finally come up with innovative solutions to creating choices for the urban poor through various solutions and multiple dimensions. One of such program is DAY-NULM (Deendayal Antyodaya Yojana- National Urban Livelihoods Mission). In Assam DAY-NULM is operating under ASULM (Assam State Urban Livelihoods Mission Society). This programme comes with various components which aim to reduce poverty and vulnerability of the urban poor households by enabling them to access gainful self employment opportunities, providing shelters equipped with essential services to the urban homeless in a phased manner. All the schemes under this programme have been started from the last month of 2014, but still some of the components are not yet implemented. They are in progress and the state government giving their full efforts for implementing this programme to reduce urban poverty of the city.

\section{REFERENCES}

[1] Bashar, T., Rashid, S. (2012). Urban microfinance and urban poverty in Bangladesh. Journal of the Asia Pacific Economy, Volume 17, No- 1, ISSN: 1354-7860 (print) 1469-9648 (online), 151-170.

[2] Chinake, H. (1997). Strategies for Poverty Alleviation in Zimbabwe. Journal of Social Development in Africa, 39-51

[3] Das, D.K (2016). Microfinance and Its Impact on Tribal Communities. Imperial Journal of Interdisciplinary Research, Volume 2, Issue-2, ISSN: 2454-1362.

[4] Dr. Chetia, P (2014). Conditions and Perceptions of the Urban Poor. IOSR Journal of Humanities and Social Science, Volume 19, Issue 7, e-ISSN: 2279-0837, p-ISSN: 2279-0845, 48-52.

[5] Dr. Suresh, D. (2012). Poverty Alleviation Programmes in India and Its Consequences. Review of Arts and Humanities, 8-30.

[6] Jegatheesan, S., Ganesh, S., Praveen, K.S (2011). Research Study about the Role of Microfinance Institutions in the Development of Entrepreneurs. International Journal of Trade, Economics and Finance, Volume 2.

[7] Malali, R.G (2016). Poverty Alleviation Programmes in Urban India. SSRG International Journal of Economics and Management Studies, Volume 3, Issue 4, ISSN: 2393 - 9125.

[8] Ray, C.N (2010). Livelihoods for the Urban Poor: A Case Study of UMEED Programme in Ahmedabad. 1-10

[9] Tela, U. (2014). Appraising Poverty Alleviation Programs of Successive Governments in Nigeria. IOSR Journal of Business and Management, Volume 16, Issue 9, ISSN: 2278-487X (online) 2319-7668 (print), 1-7. 